\title{
Neural Network Theory and Recent Neuroanatomical Findings Indicate that Inadequate Nitric Oxide Synthase Will Cause Autism
}

\author{
Lennart Gustafsson \\ Computer Science and Electrical Engineering \\ Luleå University of Technology \\ S-971 87 Luleå, Sweden \\ Lennart.Gustafsson@sm.luth.se
}

\begin{abstract}
Neural network theory indicates that inadequate expression of nitric oxide will cause narrow cortical neural columns, predicted on theoretical grounds and recently observed in autism. Another recent neuroanatomical finding in autism, early rapid growth of the cerebrum, may also be explained by inadequate expression of nitric oxide. Another long known neuroanatomical abnormality in autism, a reduced number of Purkinje cells in the Cerebellum, may also be caused, or aggravated, by inadequate expression of nitric oxide synthase. Some characteristics, such as motor impairments, sleep problems, deficit in aggression control and reduced nociception, which are not uncommon in autism, have been found in animal studies when nitric oxide synthase has been suppressed.
\end{abstract}

\section{Introduction}

Autism is a developmental disorder characterized (DSM-IV, 1994) by qualitative impairments in social interactions and in communication and by restricted, repetitive and stereotyped patterns of behavior, activities and interests. A number of theories of autism have been proposed, among them a 'theory of mind' deficit (Happé, 1994 [1]), 'executive functions' deficit (Ozonoff et al. 1991 [2], and Bishop, 1993 [3]) and 'weak central coherence' (Frith 1989 [4]). For a brief review of these theories, see Happé and Frith 1996 [5].

Even though the diagnostic criteria are behavior-based, many neurobiological abnormalities have been found to be associated with autism, for an introduction see Gillberg and Coleman 2000 [6]. These abnormalities are many and diverse and few, if any, are consistent, i.e. they are not found in all cases examined, making it difficult to build a theory of autism based on biological abnormalities. It is, however, the purpose of this paper to show that a number of biological abnormalities in autism may have one, until now overlooked, common cause. 
The cause of autism proposed in this paper is an inadequate expression of nitric oxide (NO) in CNS.

Neural network theories, or connectionist theories, (Cohen 1994 [7], Gustafsson 1997 [8]) attempt to model autism and combine information from psychology and biology. Hermelin's (Hermelin 1978 [9]) statement that children with autism "do not tend to integrate current experience with schemas and representations from previous sensory impressions" is understood to mean that they do not build adequate cortical feature maps. Models of cortical feature maps which are not adequately organized to extract features from stimuli are seen as exhibiting autistic characteristics. The cause proposed for such inadequate cortical feature maps is the same as the cause proposed for the biological abnormalities.

The synthesis of NO is widely spread in the central and peripheral nervous system, and also in the immune system. In addition it plays important roles in the cardiovascular and endocrinological systems. NO is synthesized from NOS (Nitric Oxide Synthase) of different origins. In the CNS nitric oxide synthesized from both nNOS (neuronal NOS), and eNOS (endothelial NOS) is widely spread. Particularly high concentrations of NO has been found in the cerebellum but $\mathrm{NO}$ is also prominent in cerebrum. NO has been found to be of importance for both long term potentiation (LTP) and for long term depression (LTD) in hippocampus; NO is thus important for learning. For an overview of the functions of NO in the brain, see Mize et al. 1998 [10].

\section{Columnar Organization in Cortex and in Neural Networks}

A columnar organization of neurons is common in cerebral cortex (Mountcastle 1957, 1997 [11, 12]). Likewise in models of self-organization of feature maps, a columnar organization emerges (Kohonen 1984 [13]). It has been argued (Gustafsson 1997 [8]) that columnar organization consisting of narrow columns would be inadequate for feature extraction and would therefore model autism. It has recently been shown (Casanova et al. 2002 [14]) that the neural minicolumns in frontal cortex are narrower in individuals with autism than in normal individuals.

In the early models of cortical maps (see Kohonen 1984 [13]) it was assumed that these were formed by afferent inputs to a neural network with both lateral excitatory and inhibitory connections. A balance between these different lateral connections must be present for stable neural columns to form; if the excitatory connections were weak and/or inhibitory connections strong, the resulting columns would be narrow.

It has later been shown (Gally et al. 1990 [15], Montague et al. 1991 [16], Krekelberg and Taylor 1996, 1997 [17, 18]), both through simulations and mathematical analysis, that stable cortical maps can develop without the lateral excitatory/inhibitory connections but with a "diffusing messenger", NO. The width of the excitation, i.e. the neural column, in the map was found to be dependent on the rate of production of nitric oxide with narrow widths obtained if 
NO production is low. Inadequate NO levels would thus cause narrow columns, predicted on theoretical grounds by Gustafsson and experimentally found by Casanova et al.

\section{Recent Findings Regarding Cerebral Growth}

Recent investigations of cerebral development (Carper et al. 2002 [19], Akshoomoff et al. 2002 [20], Courchesne 2002 [21], Courchesne et al. 2002 [22]) show that there is an early more rapid growth of most of cerebrum in children with autism than in normal children. The rapid growth is particularly pronounced in the frontal lobe but also in the temporal and parietal lobes, however absent in the occipital lobe. Since functions which are subserved by the frontal lobe such as social functioning are known to be impaired in autism while visual functioning, subserved by the occipital lobe is relatively spared, this early hyperplasia can arguably be related to functional impairments in autism. Carper et al. suggest that elevated levels of neurotrophins may affect neural development, e.g. axonal branching, such that an early rapid growth follows.

An equally valid explanation is that an arresting factor is absent or inadequate. Several animal studies (Peunova and Enikolopov 1993 [23], Ernst et al. 2000 [24]) show that NO acts as such an arresting factor. But could the effects of NO be limited so that the occipital lobe is not affected? The work by Csillik et al. (Csillik et al. 1998 [25]) shed some light on this question. They found that NO is important in the columnar organization of neurons in prefrontal cortex but not in area 17 in the occipital lobe. The work by Tobin et al. 1995 [26] point in the same direction. They have shown that inhibition of NOS does not impair visual or spatial discrimination. The effect of NO in cortical organization is important only in areas that were shown to grow rapidly in the recent investigations of cerebral growth. Inadequate NO could both impair organization and also not arrest neural growth in a normal way in the frontal lobe but leave the occipital lobe unaffected.

\section{Cerebellar Abnormalities in Autism}

The existence of cerebellar abnormalities in autism has long been known, with a reduced number of Purkinje cells (Ritvo et al. 1986) being a very common finding. NO is expressed in Purkinje cells and therefore a decreased level of NO could be expected to affect the functioning of those cells. It has also recently been hypothesized (Courchesne 2002 [21]) that Purkinje cells are under excitotoxic stress in children with autism at the age when the rapid growth of the cerebrum occurs.

NO has been shown to have both a neuroprotective and a neurodegenerative role (Snyder 1993 [27]). In this context it is relevant to point to the results by Ciani et al. 2001 [28] that long-lasting inhibition of NOS can aggravate the damage in excitotoxic brain injuries. 


\section{Other Common Impairments in Autism Where NO Is of Importance}

Although not part of the diagnostic criteria, motor impairments are common or even universal in autism (Minshew et al. 2002 [29]). Motor functioning involves both cerebrum and cerebellum and in this context it is relevant to point to the work by Yanigihara and Kondo 1996 [30] who find that "NO in the cerebellum plays a key role in motor learning".

Sleep problems, particularly in early childhood, has long been known to be common in autism (see Gillberg and Coleman 2000 [6]). A number of investigations indicate that NO plays a role in the regulation of sleep-wake activity. Inhibition of NO synthesis inhibits sleep in rats (Kapás et al. 1994 [31]).

Temper tantrums in children with autism is often encountered and is sometimes aggravated at onset of puberty (see Gillberg and Coleman 2000 [6]). NO has been proven to be important for the regulation of mood. Aggressive and abnormal sexual behavior has been reported in mice with suppressed NOS (Nelson et al. 1995 [32], Demas et al. 1997 [33]).

It has been observed that some individuals with autism have reduced nociception, they are less sensitive to pain from mechanical and thermal abuse (see Gillberg and Coleman 2000 [6]). NO facilitates induction of nociception (for a review see Millan 1999 [34]). NO also facilitates the maintenance of nociception, see, e.g. Yoon et al. 1998 [35]. It has been established that selective inhibitors of nNOS reduce the sensitivity to nociceptive stimuli, both mechanical and thermal, in rats, (see Handy and Coleman 1992 [36]).

\section{Conclusion}

It is claimed that the indications that deficient NO expression in the CNS will cause autism are sufficient to warrant neurophysiological investigations. If the relevant NOS activity can be upregulated then this could offer a therapeutic approach to autism in very early development.

\section{Acknowledgements}

This work is a result of a cooperation between Luleå University of Technology, Luleå, Sweden and Monash University, Clayton, Australia. I wish to express my appreciation to the Luleå STINT grant scheme and the Monash SMURF-2 grant scheme for supporting this cooperation. I also wish to thank my colleague Dr. Andrew Paplinski of Monash University for much support and Dr. Robert Schultz of Yale University for making me aware of developments I had overlooked. 


\section{References}

[1] Happé, F.: Autism: An Introduction to Psychological Theory. UCL Press, London (1994) 1109

[2] Ozonoff, S., Pennington, B., Rogers, S.: Executive function deficits in highfunctioning autisti individual: Relationship to theory of mind. Child Psychol. Psychiatry (1991) 1081-1105 1109

[3] Bishop, D.: Annotation: Autism, executive functions and theory of mind; a neuropsychological perspective. Child Psychol. Psychiatry (1993) 279-293 1109

[4] Frith, U.: Autism: Explaining the Enigma. Basil Blackwell, Oxford (1989) 1109

[5] Happé, F., Frith, U.: The neuropsychology of autism. Brain (1996) 1377-1400 1109

[6] Gillberg, C., Coleman, M.: The Biology of the Autistic Syndromes. 3rd edn. Cambridge University Press (2000) 1109, 1112

[7] Cohen, I.: An artificial neural network analogue of learning in autism. Biol. Psychiatry (1994) 5-20 1110

[8] Gustafsson, L.: Inadequate cortical feature maps: A neural circuit theory of autism. Biol. Psychiatry (1997) 1138-1147 1110

[9] Hermelin, B.: Images and language. In Rutter, M., Schoppler, E., eds.: Autism: A Reappraisal of Concept and Treatment. Plenum, New York (1978) 141-154 1110

[10] Mize, R., Dawson, T., Dawson, V., Friedlander, (eds).: Progress in Brain Research Vol 118. Elsevier Science, Amsterdam (1998) 1110

[11] Mountcastle, V.: Modality and topographic properties of single neurons of cat's somatic sensory cortex. Neurophysiology (1957) 408-434 1110

[12] Mountcastle, V.: The columnar organization of the neocortex. Brain (1997) 701$722 \quad 1110$

[13] Kohonen, T.: Self-Organising Maps. 3rd edn. Springer-Verlag, Berlin (2001) 1110

[14] Casanova, M., Buxhoeveden, D., Switala, A., Roy, E.: Minicolumnar pathology in autism. Neurology (2002) 428-432 1110

[15] Gally, J., Montague, P., Reeke, G.J., Edelman, G.: The NO hypothesis - possible effects of a short-lived, rapidly diffusible signal in the development and function of the nervous system. Proc. Natl. Acad. Sci. USA (1990) 3547-3551 1110

[16] Montague, P., Gally, J., Edelman, G.: Spatial signaling in the development of neural connections. Cereb. Cortex (1991) 199-220 1110

[17] Krekelberg, B., Taylor, J.: Nitric oxide in cortical map formation. Chemical Neuroanatomy (1996) 191-196 1110

[18] Krekelberg, B., Taylor, J.: Nitric oxide: What it can compute. Network: Comput. Neural Syst. (1997) 1-16 1110

[19] Carper, R., Moses, P., Tigu, Z., Courchesne, E.: Cerebral lobes in autism: Early hyperplasia and abnormal age effects. NeuroImage (2002) 1038-051 1111

[20] Akshoomoff, N., Pierce, K., Courchesne, E.: The neurobiological basis of autism from a developmental perspective. Developmental Psychopathology (2002) 6136341111

[21] Courchesne, E.: Abnormal early brain development in autism. Mol. Psychiatry (2002) 21-23 1111

[22] Courchesne, E.: Deciphering the puzzle: unusual patterns of brain development in autism. In: Inaugural World Autism Congress., Melbourne, Australia. (2002) 1111

[23] Peunova, N., Enikolopov, G.: Nitric oxide triggers a switch to growth arrest during differentiation of neuronal cells. Nature (1993) 450-453 1111 
[24] Ernst, A., Gallo, G., Letourneau, P., McLoon, S.: Stabilization of growing retinal axons by the combined signaling of nitric oxide and brain-derived neurotrophic factor. Neuroscience (2000) 1458-1469 1111

[25] Csillik, B., Nemecsok, J., Boncz, I., Knyihar-Csillik, E.: Nitric oxide synthase and the acetylcholine receptor in the prefrontal cortex: Metasynaptic organization of the brain. Neurobiology (1998) 383-404 1111

[26] Tobin, J., Gorman, L., Baxter, M., Traystman, R.: Nitric oxide synthase inhibition does not impair visual or spatial discrimination learning. Brain Res. (1995) 1771821111

[27] Snyder, S.: Janus faces of nitric oxide. Nature (1993) 5771111

[28] Ciani, M., Baldinotti, I., Contestabile, A.: Sustained, long-lasting inhibition of nitric oxide synthase aggravates the neural damage in some models of excitotoxic brain injury. Brain Research Bulletin (2001) 29-35 1111

[29] Minshew, N., Sweeney, J., Luna, B.: Autism as a selective disorder of complex information processing and underdevelopment of neocortical systems. Molecular Psychiatry (2002) S14-S15 1112

[30] Yanigihara, D., Kondo, I.: Nitric oxide plays a key role in adaptive control of locomotion in cat. Proc. Natl. Acad. Sci. USA (1996) 13292-13297 1112

[31] Kapás, L., Fang, J., Krueger, J.: Inhibition of nitric oxide synthesis inhibits rat sleep. Brain Res. (1994) 189-196 1112

[32] Nelson, R., Demas, G., Huang, P., Fishman, M., Dawson, V., Dawson, T., Snyder, S.: Behavioral abnormalities in male mice lacking nitric oxide synthase. Nature (1995) 383-386 1112

[33] Demas, G., Eliasson, M., Dawson, T., Kriegsfeld, L., Nelson, R., Snyder, S.: Inhibition of neuronal nitric oxide synthase increases aggressive behavior in mice. Molec. Med. (1997) 610-616 1112

[34] Millan, M.: The induction of pain: An integrative review. Progress in Neurobiology (1999) 1-164 1112

[35] Yoon, Y., Sung, B., Chung, J.: Nitric oxide mediates behavioural signs of neuropathic pain in an experimental rat model. NeuroReport (1998) 367-372 1112

[36] Handy, R., Moore, P.: Effects of selective inhibitors of neuronal nitric oxide synthase on carrageenan-induced mechanical and thermal hyperalgesia. Neuropharmacology (1998) 37-43 1112 